\title{
Involving lay participants in mental health clinical audit
}

\author{
J. A. Summers and R. F. Kehoe
}

Lay involvement in clinical audit has been advocated but rarely reported. Since carty 1994 in the mental heafth unit at Aredale, Yorkshire, lay representatives have participated in all stages of clinical audit, including selection of topics and methods, data collection and standard selting. After 8 months of lay involvement, all respondents to a brief questionnalre saw lay involvement os important, although none identilied specilic benefits that had already occurred. The paper outlines themes in respondents' perceptions of the benefits and problems of loy involvement and in their suggestions for minimising difilculties.

Lay involvement in audit has developed relatively slowly, partly due to the initial view of audit as an activity for doctors. There is still some wariness, particularly about lay involvement in the detail of individual audits but recognition of the potential benefits of lay involvement is growing (Joule, 1992) and the practice is supported by the Department of Health guidance (1994).

Where lay involvement in audit is reported, this has tended to be in monitoring the quality of care. rather than in selecting audit topics and methods, setting standards or facilitating change (Joule, 1992; Balogh \& Bond, 1995). In 1994. 95\% of hospital audit committees had no lay representattves (Buttery et al, 1994).

Examples of lay involvement in mental health services have included a users' forum identifying issues for audit (Perkins, 1994), employment of service users to interview other users (personal communication; Paul Lelliott, 1994) and a pilot scheme of lay involvement at all stages of the audit process (Balogh \& Bond, 1995). Library searches and direct enquiry of relevant voluntary organisations ${ }^{1}$ failed to reveal further examples.

In Airedale mental health unit in 1994, all relevant local voluntary sector groups were invited to provide representatives to provide user

1. Good Practices in Mental Health, King's Fund, Mental Health Foundation, MIND, National Schizophrenia Fellowship, Sainsbury Mental Health Trust, Survivors Speak Out. United Kingdom Advocacy Network, Royal College of Psychiatrists. Research and Development for Psychiatry. and carer input into audit. Current participants include the local Community Health Council, the local Mental Health Forum, Making Space (carer support for relatives of people with schizophrenia), Hearing Voices, Manic Depression Fellowship and MIND. Most of the representattves are present or past users of services. Lay participants receive training and their expenses are reimbursed.

Clinical audit meetings are held monthly to agree the agenda for audit and review findings of individual audits. In addition, working groups of two to six participants meet separately to work on individual audits.

Since early 1994, the membership of the clinical audit committee has totalled 41 , including six lay members. The average attendance is 20, including five lay members. Membership of individual audit working groups is open to any interested audit committee member and four of the eleven groups have a lay participant.

\section{The study}

After 8 months of lay involvement, the 41 audit participants were asked to give anonymous written responses to open questions on lay involvement in audit. Comments were recetved from 20 , including 16 professionals and four lay members.

\section{Findings}

The most striking finding was the strongly positive attitude to lay involvement. However, although still supportive of lay involvement, one quarter felt that there had been no discernible benefit to date.

\section{Perceived benefits of lay involvement}

Some respondents felt that audit now takes more account of user and carer perspectives and less of professionals' own needs. Some thought it would therefore achieve more significant changes. The substantial practical input from lay members was recognised. It was suggested that lay involvement in audit might help professionals and users to 
understand each other better, give users more sense of influence and even have political benefits, for example as a selling point to purchasers.

\section{Concerns about lay involvement}

Respondents mentioned several factors which can prevent lay members contributing effectively. These included limited knowledge of audit and of clinical issues, difficulties obtaining information and being at a disadvantage in the unfamiliar culture of audit meetings. Several professionals expressed concerns over confidentiality, although problems have not occurred to date, and the difficulty of achieving representative lay input. Other respondents thought lay involvement was making professionals select non-contentious topics for audit and speaking less freely.

Some thought lay members would be disillusioned and unwilling to continue participating unless audit clearly improved the service, and some predicted conflict between the aims of users and professionals and between demand-led and needs-led standards.

\section{Suggestions for minimising problems}

Ideas for helping lay members contribute more effectively included training (including training for professionals), better access to information, avoiding jargon and giving lay members encouragement and time to contribute. Some respondents thought that worries over confidentiality might be reduced by a code of practice on confidentiality and by clarifying ownership of audit reports. Among suggestions for achieving more representative lay input were more lay members, positive discrimination in favour of minority groups and ensuring that lay members have links with a recognisable constituency. Arguments were presented for direct payment to lay members for the time they gave to audit in addition to reimbursement of expenses.

Differences between professional and lay views The small numbers and open questions prevent detailed comparison between the views of different groups. However, we noted that only professionals expressed concern over confidentiality and it was mainly lay participants who commented on training and information needs and the importance of making participation feel worthwhile to lay members.

\section{Comment}

Our study was designed to identify important themes which may merit further consideration but not to accurately estimate the proportions of people with particular views (which would require larger numbers, more closed questions and a higher response rate). We note the likely nonresponse bias and assume that those holding strong views would have been more likely to respond. Less than half of the audit committee membership had been involved in the original decision to develop pay involvement, but these as a group might well be predisposed to support it.

In support of the general validity of our findings is the fact that they largely echo those found with user involvement in other activities such as service planning. The audit-specific issues which were raised, notably confidentiality, professional openness, and the importance of users understanding the role and process of audit are supported by published views on user involvement in audit (Joule, 1992; Balogh \& Bond, 1995).

Since the study, we have had one minor instance of conflict between the aspirations of lay and professional participants. One lay member was keen to use the audit programme to pilot a research questionnaire on a topic in which she was particularly interested. Despite considerable discussion the proposal could not be reworked as an audit in which the individual concerned was willing to participate.

\section{Conclusions}

Is lay involvement in audit worthwhile? Aims of demonstrating openness and willingness to listen to users and carers are arguably achieved, at least in part, through the simple act of inviting participation and treating contributions with attention and respect. In Airedale we are still adapting the audit agenda to the perceived needs of users and carers, due to the first year's agenda having been largely agreed before the involvement began. The more subtle aims of ensuring that audits take account of and benefit from lay perspectives are harder to evaluate without careful research, which we did not set out to do. Given the relatively short time period over which our unit has had lay involvement in audit, it is unsurprising that no clear benefit has as yet been achieved. None the less, there is evidently a strong positive feeling locally about its importance.

How far is the experience in the mental health unit in Airedale relevant to other locations? Introducing lay involvement to a well established audit process may be more difficult than it was in Airedale where it happened during a reorganisation of audit. It may also be more difficult where lay participation is not already happening in other areas. Individual personalities and commitment, among users and professionals, are likely to affect success.

From the experience in Airedale it is clear that lay participants can be fully involved in all stages 
of clinical audit of mental health services. While there are concerns and practical difficulties, it can nevertheless be useful and appropriate to involve participants of all backgrounds.

\section{References}

BALOGH, R. \& BOND, S. (1995) Telling it like it is. Health Service Journal, 16, 26-27.

ButTery, Y., WALSH, K., Coles, J., et al (1994) The Development of Audit. Findings of a National Survey of Health Care Provider Units in England. London: CASPE Research.

DEPARTMENT OF HEALTH (1994) The Euolution of Clinical Audit. London: Department of Health.
JouLE, N. (1992) User Involvement in Medical Audit: A Spoke in the Wheel or a Link in the Chain? London: Greater London Association of Community Health Councils.

PERKINS, R. (1994) Multidisciplinary Clinical Audit Project: Annual Report. Pathfinder Community and Specialist Mental Health Services: Springfield Hospital, Glenburnie Road. London SW17 7DJ

J. A. Summers, SHO; and *R. F. Kehoe, Consultant Psychiatrist, Department of Psychiatry, Airedale General Hospital, Skipton Road. Steeton, Keighley, West Yorkshire BD20 6TD

*Correspondence 